\title{
The interrelation between temperature regimes and fish size in juvenile Atlantic cod (Gadus morhua): effects on growth and feed conversion efficiency
}

\author{
A.K. Imsland ${ }^{1, *}$, A. Foss ${ }^{2}$, A. Folkvord ${ }^{3}$, S.O. Stefansson ${ }^{3}$ and T.M. Jonassen ${ }^{4}$ \\ ${ }^{1}$ Akvaplan-niva Iceland Office, Akralind 4, 201, Kópavogur, Iceland; ${ }^{2}$ Akvaplan-niva Bergen, Nordnesboder 5 , \\ 5005, Bergen, Norway; ${ }^{3}$ Department of Biology, University of Bergen, High Technology Centre, 5020, \\ Bergen, Norway; ${ }^{4}$ Stolt Sea-Farm ASA, Bredalsmarken 15/17, 5836 Møhlenpris, Bergen, Norway; *Author \\ for correspondence (E-mail: ai@akvaplan.niva.no)
}

Accepted 19 October 2005

Key words: active thermoregulation, behavioural growth physiology, feed conversion efficiency, optimal growth temperatures, size dependent growth

\begin{abstract}
The present paper describes the growth properties of juvenile Atlantic cod (Gadus morhua) reared at 7, 10, 13 and $16{ }^{\circ} \mathrm{C}$, and a group reared under "temperature steps" i.e. with temperature reduced successively from 16 to 13 and $10{ }^{\circ} \mathrm{C}$. Growth rate and feed conversion efficiency of juvenile Atlantic cod were significantly influenced by the interaction of temperature and fish size. Overall growth was highest in the $13{ }^{\circ} \mathrm{C}$ and the T-step groups but for different reasons, as the fish at $13{ }^{\circ} \mathrm{C}$ had $10 \%$ higher overall feeding intake compared to the T-step group, whereas the T-step had $8 \%$ higher feeding efficiency. After termination of the laboratory study the fish were reared in sea pens at ambient conditions for 17 months. The groups performed differently when reared at ambient conditions in the sea as the T-step group was 11.6, 11.5, 5.3 and $7.5 \%$ larger than $7,10,13$ and $16{ }^{\circ} \mathrm{C}$, respectively in June 2005. Optimal temperature for growth and feed conversion efficiency decreased with size, indicating an ontogenetic reduction in optimum temperature for growth with increasing size. The results suggest an optimum temperature for growth of juvenile Atlantic cod in the size range 5-50 g dropping from $14.7{ }^{\circ} \mathrm{C}$ for $5-10 \mathrm{~g}$ juvenile to $12.4^{\circ} \mathrm{C}$ for 40 $50 \mathrm{~g}$ juvenile. Moreover, a broader parabolic regression curve between growth, feed conversion efficiency and temperature as size increases, indicate increased temperature tolerance with size. The study confirms that juvenile cod exhibits ontogenetic variation in temperature optimum, which might partly explain different spatial distribution of juvenile and adult cod in ocean waters. Our study also indicates a physiological mechanism that might be linked to cod migrations as cod may maximize their feeding efficiency by active thermoregulation.
\end{abstract}

\section{Introduction}

Many fish species thermoregulate behaviourally through natural behaviour, i.e., seek out a temperature close to their optimal temperature for growth (Zinichev and Zotin 1987; Hill and Magnuson 1990; Wildhaber and Crowder 1990). Hence, temperature preferanda will tend to coincide with the optimal temperature for growth (Hill and Magnuson 1990; Gadomski and Caddell 1991). In their review of the ontogenetic effects on thermal preferences of fish, McCauley and Huggins (1979) concluded that, in some fishes, there were shifts in temperature choices towards lower temperatures for larger fish. If left for a sufficient time in a temperature gradient, 
fish will eventually 'gravitate' to a final preferred temperature (Reynolds and Casterlin 1979; Larsson 2005), defined as the final preferendum temperature (Fry 1947). For several fish species, the final preferendum temperatures are suggested to coincide with the optimal temperature for growth (McCauley and Huggins 1979) or alternatively near the optimal temperature for growth efficiency (Larsson 2005). In a laboratory trial with Arctic charr (Salvelinus alpinus) the fish selected temperature lower than its optimal temperature for growth hence maximising its growth efficiency as optimal temperature for feed conversion is suggested to be lower than temperature for optimal growth (Jobling 1997; Larsson 2005). Little is known about temperature preferendum of wild juvenile Atlantic cod (Gadus morhua L.). Studies have indicated that wild juvenile cod may inhabit areas with sub-optimal growth temperatures (Kristiansen et al. 2001) in order to optimize their probability of survival, whereas other studies indicate that migratory behaviour of cod may depend on foraging strategies (Pálsson and Thorsteinsson 2003) and can broadly be divided into deep- or shallow-water migrations. The shallow-water cod appear to follow the seasonal trend in temperature characteristic for shelf waters where large seasonal differences in temperature may occur (with maximum temperatures in late summer/autumn, and minimum temperatures in late spring). The deep-water cod, however, migrate to deeper and cooler waters and increase their vertical movement. In this scenario the shallow-water cod would be more sedentary and display higher growth but at a higher predation risk. The study of Hanson (1996) indicated that juvenile cod can be found in shallow water during summer, but migrate into deeper water during autumn and winter. This could be related to juvenile thermoregulative behaviour of the deep-water cod, where the fish avoid the low winter temperatures in shallow-water. Different spatial distributions of early-life stages and adults as a consequence of different ambient temperatures have been reported for some fish species (Fonds 1979; Gadomski and Caddell 1991) including Atlantic cod (Michalsen et al. 1998; Lafrance et al. 2005), and efforts have been made to predict distribution of fish based on the optimal temperature for growth (Bryan et al. 1990) and on the ambient temperature experienced by the fish during summer and autumn (Michalsen et al. 1998).

Fish typically show a rapid increase in relative growth rate as the temperature rises, passing through a peak at optimum temperature $\left(T_{\text {opt }} G\right)$ and falling rapidly at temperatures beyond $T_{\mathrm{opt}} G$ (cf. Brett 1979; Cuenco et al. 1985; Imsland et al. 1996; Jonassen et al. 1999). A common finding in studies examining the relationship of temperature and size on growth is that $T_{\text {opt }} G$ deceases as fish size increases (Imsland et al. 1996; Jonassen et al. 1999). To utilize this mechanism to improve growth, fish would have to be reared in "temperature steps" i.e. temperature should be lowered following changes in fish size, mimicking a mechanism suggested for wild cod (Hanson 1996; Björnsson and Steinarsson 2002). In the present study we try to mimic this different "temperaturestep" method by rearing one group of fish at three different temperatures i.e. $16^{\circ} \mathrm{C}$ followed by 13 and $10{ }^{\circ} \mathrm{C}$, and comparing growth with fish held at stable temperatures.

The aim of the present study was to characterise growth potential of juvenile Atlantic cod at early juvenile stages reared at five different temperature regimes. Four regimes consisted of constant temperatures between 7 and $16{ }^{\circ} \mathrm{C}$ and one regime was designed to follow the $T_{\mathrm{opt}} G$ for juvenile cod between 5-70 g. More specifically, we wanted to investigate how optimal temperature for growth and feed conversion efficiency varies with size and whether these differences (if any) are more pronounced at optimal temperature than at suband super-optimal temperatures.

\section{Materials and methods}

\section{Fish material and experimental rearing conditions}

The eggs were obtained from two commercial cod juvenile producers. The first group was attained from a cod hatchery in western $\left(59^{\circ} 50^{\prime} \mathrm{N}\right)$, Norway and transported to the facilities of the University of Bergen were they were incubated. The broodfish were wild caught in the area around Bømlo (W-Norway) in 2003 and reared in $40 \mathrm{~m}^{3}$ tanks at simulated natural photoperiod and temperature of $6-8{ }^{\circ} \mathrm{C}$ (sea water pumped from $160 \mathrm{~m}$ depth). The mean weight of the broodfish was approx. $7 \mathrm{~kg}$ (range $5-18 \mathrm{~kg}$ ). The eggs hatched on 
28 March and the larvae were subsequently transferred to a 5001 tank with a constant temperature of $7.8^{\circ} \mathrm{C}$. The larvae were reared under continuous light, fed fresh filtered natural zooplankton (gradually increasing size fraction from 80 to $1000 \mu$ ) and weaned on a commercial formulated feed (Marin 030 and 050, Ewos A/S, Bergen, Norway) containing $60 \%$ protein, $12 \%$ fat and $12 \%$ carbohydrates. On 20 June 2003 the juveniles were brought to the Industrial and Aquatic Laboratory at the Bergen High Technology Centre and reared at $10{ }^{\circ} \mathrm{C}$ and simulated natural photoperiod $\left(\mathrm{LDN}, 60^{\circ} \mathrm{N}\right)$. This light regime was used throughout the acclimation and experimental period.

The aforementioned group of fish, which was startfed on natural zooplankton, was mixed with an equal number of fish originating from another cod hatchery from western $\left(61^{\circ} 40^{\prime} \mathrm{N}\right)$, Norway. The broodfish were wild caught in the area around Møre (W-Norway) in 2003 and reared in $70 \mathrm{~m}^{3}$ tanks at simulated natural photoperiod and temperature of $6-8{ }^{\circ} \mathrm{C}$ (sea water pumped from $100 \mathrm{~m}$ depth). The mean weight of the broodfish was approx. $15 \mathrm{~kg}$ (range $7-22 \mathrm{~kg}$ ). This group was first fed in an intensive system using enriched rotifers for 25 days and subsequently fed the same commercial feed as the group described above (Ewos Marin 030 and 050). On 22 June the fish were transported to the Industrial and Aquatic Laboratory at the Bergen High Technology Centre and reared under the same conditions as described above.

The fish $(n=1123)$ from the two groups were mixed and distributed randomly into 10 rearing tanks. The $1 \mathrm{~m}^{2}$ square, grey, covered fiberglass experimental tanks had a rearing volume of 4001 and a bottom outlet. Seawater with a salinity of $33.5 \%( \pm 0.2 \%$ oo was pumped from $90 \mathrm{~m}$ depth. Water flow was set to $101 \mathrm{~min}^{-1}$ for all experimental tanks. Oxygen saturation was measured weekly in the effluent (i.e. bottom outlet) water of all tanks and was higher than $80 \%$ at all times. A $36 \mathrm{~W}$ fluorescent daylight tube integrated in the tank-cover provided light. Photon-irradiation measured at the bottom of the tanks was ca. $5 \mu \mathrm{mol} \mathrm{m}{ }^{-2} \mathrm{~s}^{-1}$. Prior to, and during the experiment, the juveniles were fed a commercial formulated feed (Marin 10 and 20, Ewos A/S) containing $55 \%$ protein, $12 \%$ fat and $11 \%$ carbohydrate. Pellet size (2 and $3 \mathrm{~mm}$ ) was adjusted during the experiment, depending on fish size with an introduction of $3 \mathrm{~mm}$ pellets from 14 October.

The growth study was carried out from 8 September until 12 December 2003. On 25 August 2003, in preparation for the study, a subgroup within each tank $\left(n=40-41\right.$ in each tank, $\left.n_{\text {total }}=484\right)$ were tagged intraperitoneally with Trovan ${ }^{\circledR}$ Passive Transponder tags, and gradually acclimated over one day $\left(7\right.$ and $13{ }^{\circ} \mathrm{C}$ groups) or three days $\left(16{ }^{\circ} \mathrm{C}\right.$ and temperature-step groups) to the five experimental temperatures regimes of $7,10,13,16^{\circ} \mathrm{C}$ and temperature-step group (T-step group). Each temperature regime consisted of two replicate tanks. The temperature-step regime was as follows: $16{ }^{\circ} \mathrm{C}$ from 9 September to 7 October; $13{ }^{\circ} \mathrm{C}$ from 8 October to 19 November; $10^{\circ} \mathrm{C}$ from 20 November to 12 December. This group is supposed to mimic temperature conditions found in Norwegian waters in late summer and autumn (Anon 2005). The mean rearing temperature in this group was $13.2^{\circ} \mathrm{C}$. The temperature in all groups was measured twice daily, and remained within $\pm 0.2{ }^{\circ} \mathrm{C}$ (SD) of that prescribed. All fish were anaesthetised (metacain, $\left.0.05 \mathrm{~g} \mathrm{l}^{-1}\right)$, and weighed individually $(0.1 \mathrm{~g})$ at $22-$ 28 days interval during the experiment.

Feed was provided in excess for two $30 \mathrm{~min}$ periods daily (09:00-09:30 $\mathrm{h}$ and 14:30-15:00 h). Uneaten pellets were collected after each feeding (no later than $30 \mathrm{~min}$ after each feeding pulse) by filtering the outlet water with a fine mesh and counted to estimate feed intake and feed conversion efficiency.

\section{Rearing in sea pens}

After termination of the temperature trial all individual fish $(n=473)$ were acclimatized to $10{ }^{\circ} \mathrm{C}$ and transported by truck on January 152004 to the production site of Marine Harvest at Smøla (W-Norway, 6331') where the fish are reared at ambient temperatures (mean temperature $15^{\circ} \mathrm{C}$ in August, mean temperature $5{ }^{\circ} \mathrm{C}$ in March) in sea pens $\left(40 \mathrm{~m}\right.$ in diameter, $7 \mathrm{~m}$ deep, $1000 \mathrm{~m}^{3}$ in volume). The fish were reared together with 7500 other (untagged) cod in one sea pen. Mean weight at start (all fish) was $172 \mathrm{~g}$ and the total biomass in the sea pen was approx. $9000 \mathrm{~kg}$ at start. The fish were hand fed five times a week using a commercial formulated feed from Ewos (Ewos Cod feed, 5-13 mm). On June 292005 we conducted a sampling where weight of 158 tagged fish from the 
temperature study was measured. Number of fish in June 2005 was 7700 with an average weight (all fish) of $1200 \mathrm{~g}$.

\section{Data analysis and statistical methods}

Total feed consumption $\left(C_{\mathrm{T}}\right)$ was calculated as total feed supplied - total remaining feed. $C_{\mathrm{T}}$ was calculated on a daily basis and then summarized for each period. Daily feeding rate $(F \%)$ was calculated as

$$
F \%=100\left[C /\left(\left(B_{1}+B_{2}\right) / 2\right)\right]\left(t_{2}-t_{1}\right)^{-1}
$$

where, $C$ is feed consumption (g) in the period and $B_{1}$ and $B_{2}$ are fish biomass $(\mathrm{g})$ on days $t_{1}$ and $t_{2}$ respectively. Feed conversion efficiency (FCE) was calculated as biomass gain per unit weight of feed consumed:

$$
\mathrm{FCE}=\left(B_{2}-B_{1}\right) / C
$$

Specificgrowth rate (SGR) was calculated according to the formula of Houde and Schekter (1981):

$$
\mathrm{SGR}=\left(\mathrm{e}^{g}-1\right) 100
$$

where, the instantaneous growth coefficient $g$ is

$$
g=\left(\ln W_{2}-\ln W_{1}\right)\left(t_{2}-t_{1}\right)^{-1}
$$

and $W_{2}$ and $W_{1}$ is wet weight (g) at days $t_{2}$ and $t_{1}$, respectively.

SGR was regressed against geometric mean weight $(\mathrm{GM})$, where $\mathrm{GM}$ is: $\mathrm{GM}=\left(W_{1} W_{2}\right)^{1 / 2}$. To avoid pseudoreplication, data for tagged fish $(N=30-50)$ in each tank were combined in this regression.

In calculation of the temperature effect on growth rate, $Q_{10}$ of growth was calculated according to:

$$
Q_{10}=\left(G_{2} G_{1}^{-1}\right)^{10\left(T_{2}-T_{1}\right)^{-1}}
$$

where, $G_{1}$ and $G_{2}$ are observed specific growth rates at temperatures $T_{1}$ and $T_{2}$ (Schmidt-Nielsen 1990).

All statistical analyses were performed with STATISTICA $^{\mathrm{TM}}$ 6.0. To assess normality of distributions a Kolmogorov-Smirnov test was used and homogeneity of variances was tested using the Levene's $F$ test. Two-way nested ANOVA (Zar 1984), where replicates are nested within the temperatures, was applied to calculate the effect of different temperatures on mean weights and specific growth rates. Significant ANOVAs were followed by a Student-Newman-Keuls multiple comparison test to locate differences among treatments (Zar 1984). For weight data of fish in sea pen we used a Fisher LSD unequal $N$ test to locate differences as the number of fish was unequal between the groups. For parameters where only group data existed ( $F C E, F \%$ and $C_{\mathrm{T}}$ ) a two way nested ANOVA (Zar 1984) was applied, followed by a Student-Newman-Keuls multiple comparison test to locate any differences among treatments (Zar 1984). Individual growth trajectories were analysed using a growth curve analysis model (GCM, Chambers and Miller 1995) which is an extension of the multivariate repeated measurements analysis of variance (MANOVA) model. The model equation of the GCM had the form:

$$
\mathbf{Y}(n \times p)=\mathbf{X}(n \times q) \mathbf{B}(q \times p)+\mathbf{E}(n \times p)
$$

where $\mathbf{Y}(n \times p)$ are the growth at age vectors $\mathbf{y}=\left(y_{1}, y_{2}, \ldots, y_{p}\right)$ for each $p$ (age) measurements on $\mathrm{n}$ individual fish; $\mathbf{X}(n \times q)$ is the design matrix or the set of extraneous variables measured for each individual, i.e., $q=$ age $_{p}+$ temperature $_{i} ;(i=7$, $10,13,16{ }^{\circ} \mathrm{C}$ and T-step); $\mathbf{B}(q \times p)$ is the matrix of parameters estimated by the model; $\mathbf{E}(n \times p)$ is the matrix of deviations for each individual from the expected value of $\mathbf{Y}=\mathbf{X B}$

Analyses were made for all temperatures combined and for each temperature separately. Size specific growth was analysed with a parabolic regression (Zar 1984) where $G$ was regressed against temperature for three size classes; 5-10, 20-30, and 40-50 g. To be able to conduct this analysis for the $7{ }^{\circ} \mathrm{C}$ group we had to make a selection for fish in the largest (i.e. 40-50 g) size range. The regression was made using the combined growth rates of all tagged fish at each temperature for the chosen size intervals. Optimal temperatures for growth $\left(T_{\text {opt }} G\right)$ were calculated as the zero solution to the first derivative of the parabolic regression equations i.e. the solution of:

$$
G=a T^{2}+b T+c \text { or } d G / d T=0 \rightarrow T_{\mathrm{opt}} G=-b / 2 c
$$

where, $G=$ specific growth rate, $T=$ temperature $\left({ }^{\circ} \mathrm{C}\right)$, and $a, b$ and $c$ are constants determined by the regression. Asymptotic standard error of mean 
(SEM) for $T_{\text {opt }} G$ was calculated based on individual growth data. Similar regressions were made for three size classes (i.e. 8-12, 18-32 and 32-50 g) of Atlantic cod for the feed conversion efficiency data ( $\left.T_{\text {opt }} \mathrm{FCE}\right)$. Here the asymptotic standard error of mean was based on group data.

The $G$ versus GM regressions were analysed using covariance analysis (ANCOVA, Sokal and Rohlf 1995), the ANCOVA being run with size as a covariate. The model equation of the ANCOVA had the form (Schéffe 1959):

$$
X_{i j}=\mu+\alpha_{i}+\gamma\left(z_{i j}-\bar{z}\right)+\varepsilon_{i j}
$$

where, $\mu$ is the overall mean, $\alpha_{\mathrm{i}}$ is the treatment effect of the temperature groups, $\gamma$ is the regression coefficient for the $G$-GM regression, $z_{i j}$ is the geometric mean weight of the fish (covariable) and $\varepsilon_{\mathrm{ij}}$ the error term. Size ranking (initial size rank vs. final size rank) and growth ranking (initial growth vs. final growth) was tested using Spearmans rank correlation $\left(r_{\mathrm{Sp}}\right.$ Zar 1984). $r_{\mathrm{Sp}}$ was also used to test the correlation between the total thermal sum $\left(T_{\mathrm{SUM}}\right)$ for each replicate defined as:

$$
T_{\mathrm{SUM}}=\sum_{i=1}^{n} T_{i}
$$

where $T_{i}$ is the temperature at day $i=1$ at start ( 8 September) and $n$ the temperature at termination of the experiment (13 December). A significance level $(\alpha)$ of 0.05 was used if not stated otherwise. In cases with non-significant statistical tests, power $(1-\beta)$ analysis were performed using the PASS program package (Hintze 1996) using $\alpha=0.05$.

\section{Results}

\section{Mortality}

Total mortality was $2.3 \%$ (11 fish). No systematic trend was found as mortality occurred in all rearing units except for the T-step group $\left(7^{\circ} \mathrm{C}=5\right.$ fish; $10{ }^{\circ} \mathrm{C}=2$ fish; $13{ }^{\circ} \mathrm{C}=1$ fish; $16{ }^{\circ} \mathrm{C}=3$ fish, $\chi^{2}<2.2, p>0.2$ ). Ten of the dead fish were registered from 16-19 November. A size-dependent mortality was found on 19 November as the dead fish were significantly smaller than the surviving fish at both 7 and $16{ }^{\circ} \mathrm{C}$ (one way ANOVA, $p<0.05$ ).

\section{Effect of temperature on growth}

The overall initial mean weight (sd) was $8.9(0.3) \mathrm{g}$ and did not differ (two way nested ANOVA, Power $(1-\beta)>0.9)$ among the groups. The T-step and $13{ }^{\circ} \mathrm{C}$ had the highest final mean weight $(51.4 \mathrm{~g}$ in both groups, two way nested ANOVA, $p<0.05$, Figure 1). From early October onwards the $7{ }^{\circ} \mathrm{C}$ group had lowest mean weights (two way nested ANOVA, $p<0.01$ ) of all the groups, whereas the 10 and $16{ }^{\circ} \mathrm{C}$ group ranked in-between. The final mean weights of the T-step and $13{ }^{\circ} \mathrm{C}$ groups were 11 and $12 \%$ higher than those of the 10 and $16{ }^{\circ} \mathrm{C}$ groups, respectively. Mean individual growth trajectories were different (GCM, MANOVA TEM- $_{\text {- }}$ PERATURE, Wilk's lambda (M) $16,1329=0.36, p<0.001$, Figure 2) between the five temperatures throughout the study period. Significant differences were also found in growth-at-age trajectories of the experimental groups (MANOVA TEMPERATURE $\times$ AGE, Wilk's $\mathrm{M}_{12,1153}=0.46, p<0.001$, Figure 2) from early September onwards. In the first period the juvenile cod at 13 and $16^{\circ} \mathrm{C}$ displayed the highest growth, whereas the juveniles at $7^{\circ} \mathrm{C}$ had

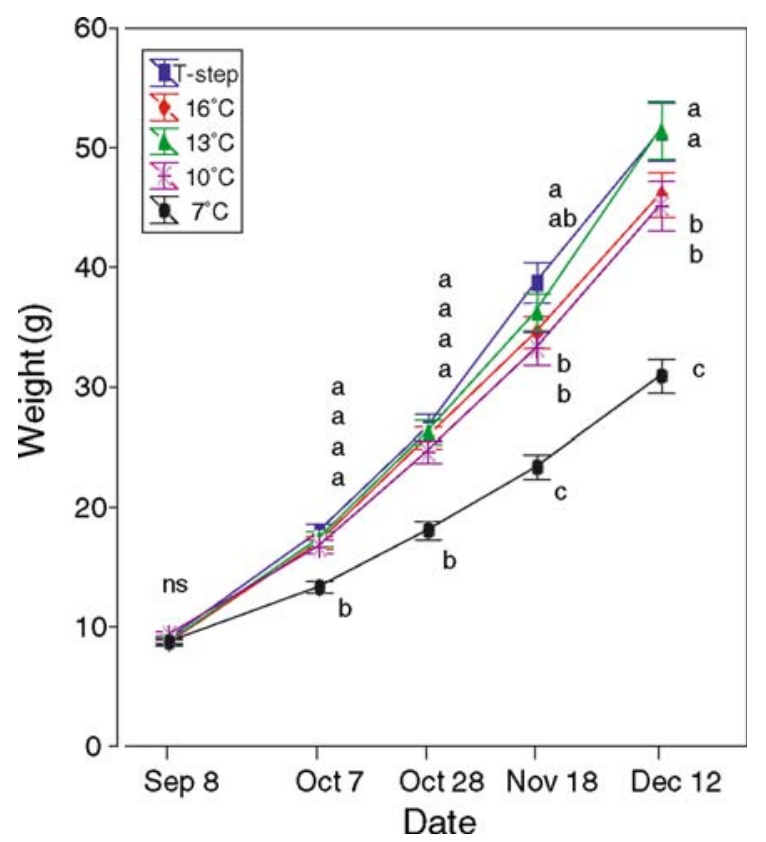

Figure 1. Mean weight of juvenile Atlantic cod reared at five different temperature regimes. Vertical line indicating SE may be obscured by symbol. Different letters indicate statistical differences (two-way nested ANOVA, $p<0.05$ ), with 'a' as the highest value. The values for two replicates are combined; $n=80-82$ for each mean value; $n s=$ not significant. 


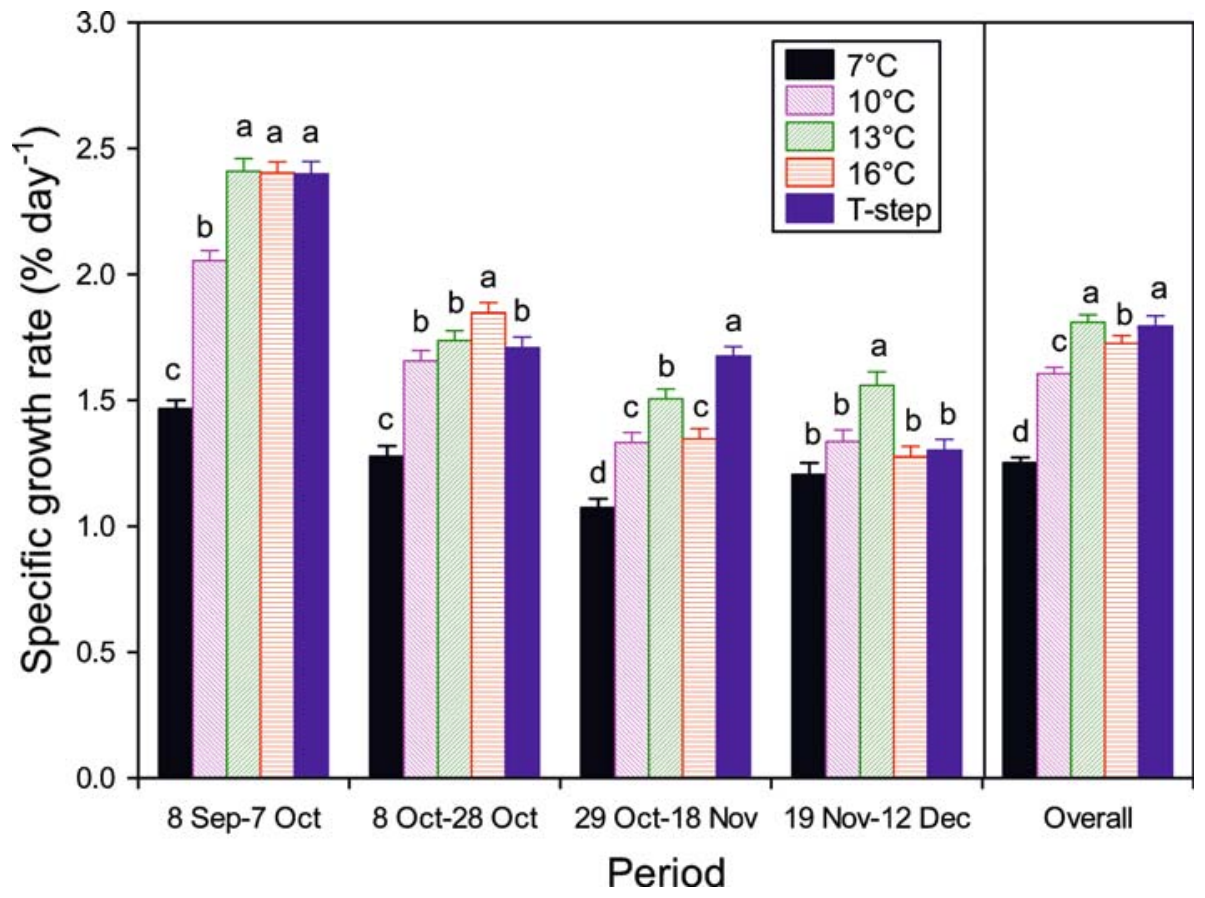

Figure 2. Mean specific growth rates of individually tagged Atlantic cod reared at five temperature regimes during the experimental period. Vertical whiskers SEM. Different letters denote significant differences (Student-Newman-Keuls test, $p<0.05$ ) within each temperature regime, $n=80-82$ for each mean value.

the slowest growth of all groups from September until November (Student-Newman-Keuls test, $p$ $<0.05)$. Growth in all groups except the $7^{\circ} \mathrm{C}$ group declined between September and December. The overall growth rate was highest at $13{ }^{\circ} \mathrm{C}$ and T-step $\quad\left(1.80 \% \mathrm{day}^{-1}\right.$, Student-Newman-Keuls test, $p<0.05)$ and lowest at $7{ }^{\circ} \mathrm{C}\left(1.25 \%\right.$ day $\left.^{-1}\right)$, while the 10 and $16{ }^{\circ} \mathrm{C}$ groups had overall growth rates of: 1.61 and $1.71 \%$ day $^{-1}$ respectively (Figure 2). $\mathrm{Q}_{10}$ of overall specific growth rate was 2.2 between 7 and $10{ }^{\circ} \mathrm{C}, 1.5$ between 10 and $13{ }^{\circ} \mathrm{C}$ and 0.8 between 13 and $16{ }^{\circ} \mathrm{C}$. Overall there was a significant positive correlation between thermal sum and growth $\left(r_{\mathrm{Sp}}=0.71, p<0.01\right)$.

\section{Effect of fish size on growth}

The size specific growth rate differed between the temperature groups. In the $7{ }^{\circ} \mathrm{C}$ group growth rate did not change with increasing weight (linear regression, $p>0.05$, Figure $3 a, 1-\beta>0.75$ ), whereas growth rate declined with size at the other temperatures (linear regression, $p<0.05$, Figure $3 b-e$ ). The regression lines for the five temperature groups were non-parallel (ANCOVA, Table $1, p<0.001$ ) as the slope for $7{ }^{\circ} \mathrm{C}$ deviated from all other slopes, and the specific growth rates were highly correlated with size (ANCOVA, $p<0.01$, Table 1).

The same trend of declining growth rates was seen when growth rates were plotted against temperature for three size classes of juvenile cod (5-10 g, 20-30 g, and 40-50 g, Figure 4). The resulting parabolic regressions (Figure 4) indicated that the temperature optimum for maximum growth in juvenile cod ( $T_{\text {opt }} G \pm \mathrm{SE}$ ) declines with size, and were estimated to be $14.7 \pm 0.5^{\circ} \mathrm{C}$ for 5 $10 \mathrm{~g}, 12.9 \pm 0.3^{\circ} \mathrm{C}$ for $20-30 \mathrm{~g}$, and $12.6 \pm 0.2^{\circ} \mathrm{C}$ for $40-50 \mathrm{~g}$ fish (Figure $4 \mathrm{a}-\mathrm{c}$, respectively, Table 2).

\section{Size and growth ranking}

A significant size rank correlation (initial weight versus final weight) was maintained at all temperature regimes $\left(r_{\mathrm{Sp}}>0.62, p<0.05\right)$. The size rank correlation was highest at $7{ }^{\circ} \mathrm{C}\left(r_{\mathrm{Sp}}=0.82\right)$ and lowest at $13{ }^{\circ} \mathrm{C}\left(r_{\mathrm{Sp}}=0.62\right)$. Also, there was an overall significant positive correlation between 

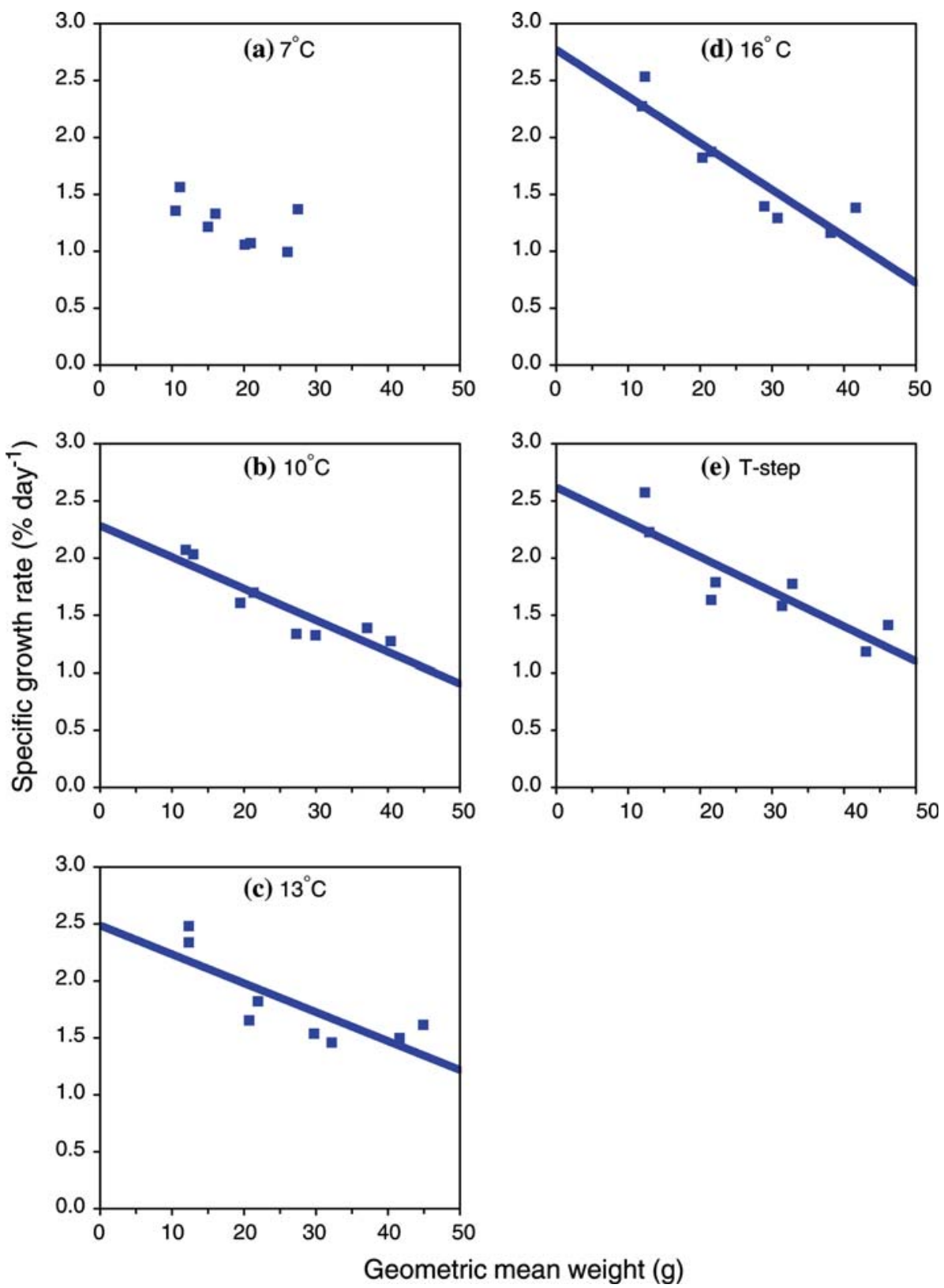

Figure 3. Specific growth rate (SGR) versus geometric mean weight (GM) of juvenile Atlantic cod. Each data point is the mean of 3950 individually tagged fish from each replicate. (a) $7{ }^{\circ} \mathrm{C}: \mathrm{SGR}=1.56-0.016 \mathrm{GM}, p>0.15$, (b) $10{ }^{\circ} \mathrm{C}: \mathrm{SGR}=2.28-0.027 \mathrm{GM}$, $p<0.01$, (c) $13{ }^{\circ} \mathrm{C}: \mathrm{SGR}=2.48-0.025 \mathrm{GM}, p<0.05$, (d) $16{ }^{\circ} \mathrm{C}: \mathrm{SGR}=2.77-0.041 \mathrm{GM}, p<0.01$, (e) T-step: SGR $=2.62-0.030 \mathrm{GM}$, $p<0.01 . n=8$ for all groups.

adjacent growth rates (i.e. week $_{n}$ and week $_{\mathrm{n}+\mathrm{i}}$ ) in all temperature groups at all dates. Accordingly, initial vs. final growth rates were significantly correlated at all temperatures $\left(r_{\mathrm{Sp}}=0.33, p<0.05\right)$.
Feed intake and feed conversion efficiency

Feed consumption $\left(C_{\mathrm{T}}\right)$ and daily feeding rate $(F \%)$ differed between temperature regimes (Table 3 ). 
Table 1. Analysis of covariance (ANCOVA) for the regression of specific growth rate (SGR, \% $\mathrm{day}^{-1}$ ) against geometric mean $($ covariate $=\mathrm{GM})$ weight $(W, \mathrm{~g}$ wet weight $)$ at different temperatures $\left(T,{ }^{\circ} \mathrm{C}\right) ; \mathrm{df}=$ degrees of freedom

\begin{tabular}{llllll}
\hline $\begin{array}{l}\text { Source of } \\
\text { variation }\end{array}$ & $\begin{array}{l}\text { Sum of } \\
\text { squares }\end{array}$ & df & $\begin{array}{l}\text { Mean } \\
\text { square }\end{array}$ & F-ratio & $\mathrm{p}$ \\
\hline $\begin{array}{l}\text { Main effect } \\
\text { Temperature (T) }\end{array}$ & 3.27 & 4 & 0.81 & 18.8 & $<0.01$ \\
$\begin{array}{l}\text { Covariate } \\
\text { GM weight (W) }\end{array}$ & 3.66 & 1 & 3.66 & 84.6 & $<0.001$ \\
$\begin{array}{l}\text { Interaction } \\
\text { T } \times \text { W }\end{array}$ & 5.31 & 5 & 1.06 & 24.5 & $<0.001$ \\
Residual & 1.47 & 34 & 0.04 & & \\
\hline
\end{tabular}

The $13{ }^{\circ} \mathrm{C}$ had the highest feed consumption and $7^{\circ} \mathrm{C}$ the lowest consumption. Across temperatures the $7{ }^{\circ} \mathrm{C}$ group had the lowest $F \%$ whereas the 13 and $16{ }^{\circ} \mathrm{C}$ and T-step groups displayed similar daily feeding rates. Feed conversion efficiency (FCE) differed between temperatures (two way nested ANOVA, $\left.F_{4,35}=2.7, p<0.05\right)$. Overall the T-step group had the highest FCE (1.28) being significantly higher than FCE in the 7 and $10{ }^{\circ} \mathrm{C}$ groups. The optimal temperature for FCE $\left(T_{\mathrm{opt}} \mathrm{FCE}\right)( \pm \mathrm{SE})$ varied among size classes (Figure 5, Table 4), although the range was less than for growth rate. $T_{\text {opt }} \mathrm{FCE}$ was estimated to be $11.3{ }^{\circ} \mathrm{C}$ for $8-12 \mathrm{~g}$ juvenile cod and $12.2{ }^{\circ} \mathrm{C}$ for the other two size classes (18-32 and 32-50 g).

\section{Growth in the sea}

The mean weight of fish reared at different temperatures during early juvenile stage did differ after rearing the fish in sea pens at ambient conditions for 17 months (Student-Newman-Keuls test, $p<0.05$, Figure 6). On June 292005 the mean weight of the T-step fish from the laboratory experiment was largest $(1.70 \mathrm{~kg}, n=29)$, followed by the $13{ }^{\circ} \mathrm{C}$ fish $(1.61 \mathrm{~kg}, n=43)$, the $16^{\circ} \mathrm{C}$ $(1.57 \mathrm{~kg}, n=20)$, the $10^{\circ} \mathrm{C}(1.51 \mathrm{~kg}, n=36)$, and with the smallest fish from the $7^{\circ} \mathrm{C}$ group $(1.20 \mathrm{~kg}, n=26)$.

\section{Discussion}

Growth rate and feed conversion efficiency of juvenile Atlantic cod were significantly influenced by temperature and fish size. In the first part of the experiment juvenile cod at $16{ }^{\circ} \mathrm{C}$ had the highest growth rate $\left(2.19 \% \mathrm{day}^{-1}\right.$, Figure 2$)$, whereas juvenile cod reared at T-step regime and at $13{ }^{\circ} \mathrm{C}$ had the highest growth rates in the latter stages of the experiment. Overall growth rates were highest at $13{ }^{\circ} \mathrm{C}$ and the $\mathrm{T}$-step groups $\left(1.80 \% \mathrm{day}^{-1}\right.$ in both groups). It is notable that although growth rates and biomass increase were similar in these two groups the physiological basis differs as the fish at $13{ }^{\circ} \mathrm{C}$ had $10 \%$ higher overall feeding intake compared to the T-step group, whereas the T-step had $8 \%$ higher feeding efficiency. It may be that different feeding dynamics are to some extent be reflected in the behaviour of cod. Robichaud and Rose (2004) reviewed a century of tagging studies with Atlantic cod and found that of all cod groups investigated $41 \%$ could be categorized as sedentary, $20 \%$ as dispersers and $38 \%$ as homers (i.e. deep water foraging in the paper by Pálsson and Thorsteinsson 2003). Moreover, Robichaud and Rose (2004) found that it was the sedentary cod groups that had lower maximum historical biomass, confirming that migration begets abundance. This effect would mostly be attributed to secondary effect of migration as migrating cod can better exploit the seasonal changes in productivity. Our data point to another positive effect of migration as cod moving from high to low temperature might also increase their feeding efficiency and energy utilisation, thus adding to larger biomass of migrating cod as compared to sedentary cod. The T-step rearing regime mimics the mechanism of behavioural thermoregulation where juveniles may seek temperatures maximising their fitness (Michalsen et al. 1998: Kristiansen et al. 2001). In some species juveniles seek out a temperature close to their optimal temperature for growth (Zinichev and Zotin 1987; Hill and Magnuson 1990; Wildhaber and Crowder 1990), whereas other species seek to maximise their feeding efficiency. Björnsson et al. (2001) postulated that cod migrations around Iceland are, at least partly, driven by feeding and optimal foraging mechanism i.e. seeking out temperatures that maximises feeding efficiency. In a natural environment, these temperatures could be much lower than what has been found in laboratory experiments, as $T_{\text {opt }} G$ decreases with decreased feed availability (Jobling, 1994).

The current study shows that fish following its $T_{\text {opt }} G$ gradient will benefit in terms of higher feeding efficiency (Table 4) and the effect can be apparent 
after the fish has moved from higher to lower temperature (Figure 5). Moreover, the groups performed differently when reared at ambient conditions in the sea (Figure 6) as the T-step group was $11.6,11.5,5.3$ and $7.5 \%$ larger than $7,10,13$ and $16{ }^{\circ} \mathrm{C}$, respectively in June 2005 . Based on this observation and the fact that the T-step rearing regime had, together with the $13{ }^{\circ} \mathrm{C}$ group, the
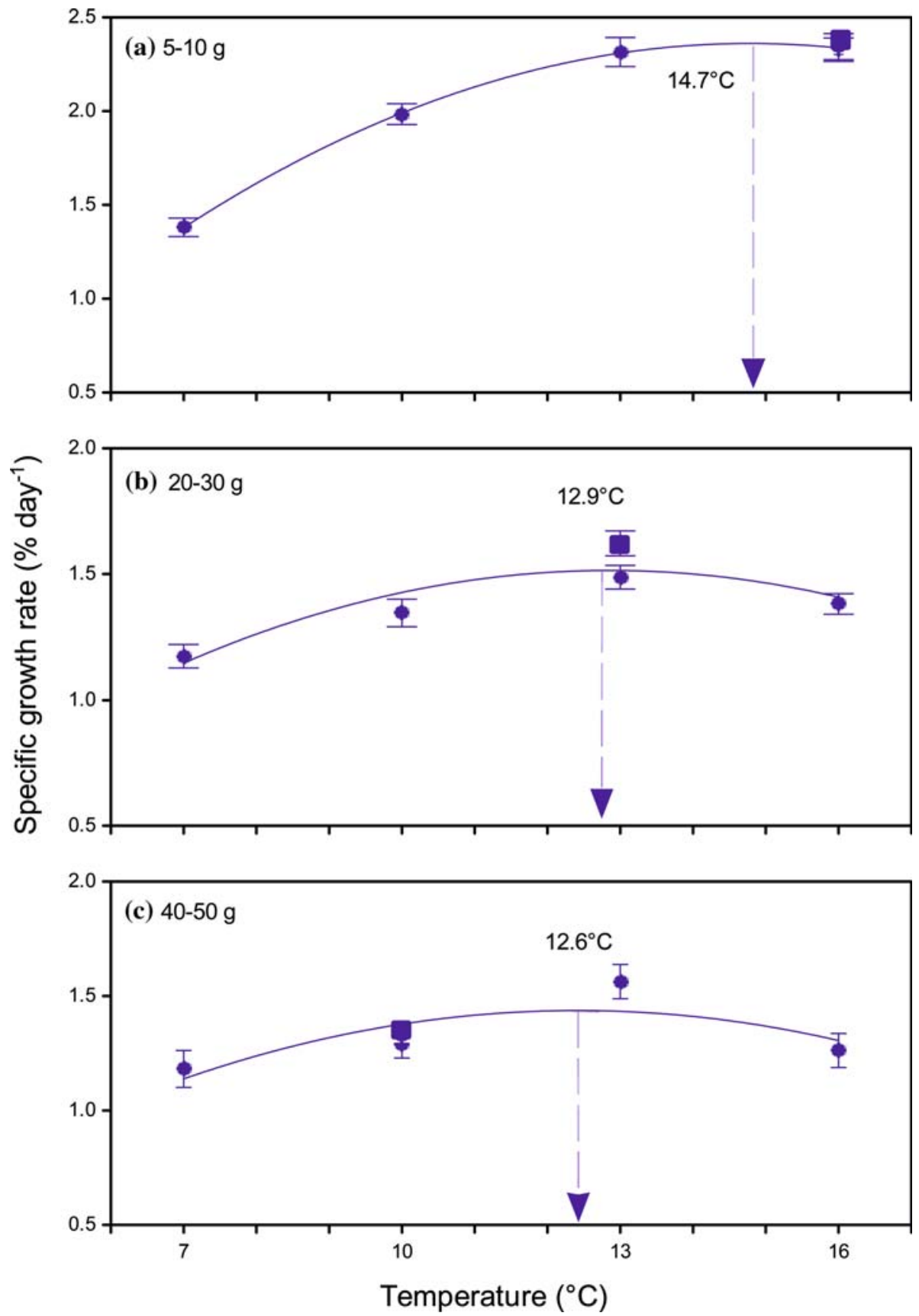

Figure 4. Changes in specific growth rate (SGR) with temperature for three different size classes of juvenile Atlantic cod. The lines represent the least-squares second order polynomial fit to the data: $\mathrm{SGR}=a T^{2}+b T+c$ where $\mathrm{SGR}=\mathrm{Specific}$ growth rate, $T=$ temperature, and $a, b$ and $c$ are constants determined by the regression. Vertical lines indicate standard error of mean, $n=30-40$ for each data point. The T-step group is marked by square symbol. For the three size classes optimum temperature for growth $\left(T_{\mathrm{opt}} G\right)$ indicated by the broken lines were calculated from the first order derivative of the parabolic regressions (i.e. when $d G / d T=0$ ). 
Table 2. The relationship between growth rate (SGR) and temperature in ${ }^{\circ} \mathrm{C}(T)$ estimated by a second order polynomial $\left(G=a T^{2}+b T+c\right)$ for different weight range of juvenile Atlantic cod

\begin{tabular}{lllllllll}
\hline Weight range & \multicolumn{1}{l}{$\mathrm{a}$} & $\mathrm{b}$ & $\mathrm{c}$ & $\mathrm{n}$ & $\mathrm{r}^{2}$ & $\mathrm{~T}_{\text {opt }} \mathrm{G}$ & $\pm \mathrm{SE}$ range & $\mathrm{G}_{\text {max }}$ \\
\hline $5-10$ & -1.191 & 0.481 & -0.016 & 259 & 0.39 & 14.7 & $14.2-15.2$ & 2.35 \\
$20-32$ & 0.309 & 0.283 & 0.011 & 252 & 0.13 & 12.9 & $12.6-13.2$ & 1.51 \\
$40-50$ & 0.178 & 0.256 & 0.010 & 271 & 0.20 & 12.6 & $12.4-12.8$ & 1.43 \\
\hline
\end{tabular}

$G_{\max }$ is the growth rate at optimal temperature.

highest overall growth rates in the temperature trial, we postulate that rearing fish at downward temperature regime (i.e. T-step) may result in long term positive effect on feeding efficiency and growth in juvenile cod. The changes that occur during thermal acclimation involve a series of adaptations at the enzymatic level that may lead to higher feed efficiency. There is some evidence that downward thermal acclimation (i.e. moving fish from higher to lower temperature) may result in increased activities in enzymes involved in aerobic energy liberation and ion transport in muscle (Jobling 1994) and increased digestive enzyme activity (Kuzmina et al. 2003). Optimal temperature for enzymatic activity can vary with size (Luszkovich and Stellwag, 1993). Accordingly, the fish in the T-step group may have been reared closer to optimal temperatures for enzymatic activity than the fish in the constant temperature groups. The data for different periods in the temperature trial show that FCE is indeed improved in line with reduced temperature in the Tstep group. FCE improved from 1.0 to 1.2 to 1.35 when reared at 16,13 and $10^{\circ} \mathrm{C}$, respectively. In contrast, FCE remained stable throughout the trial in the other temperature groups.

In other demersal fish species the positive effect of $T_{\text {opt }} G$ rearing scheme has been noted. When studying growth of spotted wolffish (Anarhichas

Table 3. Feed consumption $\left(C_{\mathrm{T}}\right)$, daily feeding rate $(F \%)$ and feed conversion efficiency (FCE) of juvenile Atlantic cod reared under five temperature regimes

\begin{tabular}{llll}
\hline Temperature $\left({ }^{\circ} \mathrm{C}\right)$ & $\mathrm{C}_{\mathrm{T}}(\mathrm{g}$ ww $)$ & $\mathrm{F} \%$ & $\mathrm{FCE}$ \\
\hline 7 & $428.3(41.4)^{\mathrm{b}}$ & $1.07(0.15)^{\mathrm{b}}$ & $1.11(0.13)^{\mathrm{b}}$ \\
10 & $655.3(78.9)^{\mathrm{b}}$ & $1.31(0.22)^{\mathrm{ab}}$ & $1.14(0.06)^{\mathrm{b}}$ \\
13 & $883.7(149.9)^{\mathrm{a}}$ & $1.45(0.27)^{\mathrm{a}}$ & $1.19(0.06)^{\mathrm{a}}$ \\
16 & $839.1(71.9)^{\mathrm{a}}$ & $1.45(0.38)^{\mathrm{a}}$ & $1.17(0.06)^{\mathrm{ab}}$ \\
T-step & $800.9(59.3)^{\mathrm{a}}$ & $1.42(0.39)^{\mathrm{a}}$ & $1.28(0.05)^{\mathrm{a}}$ \\
\hline
\end{tabular}

Results are given as mean (standard deviation), $n=8$ for each temperature regime. Different letters denote significant differences (two way nested ANOVA, $p<0.05$ ) between temperature treatments. minor) larvae up to 63 days after hatching (0.2$3 \mathrm{~g}$ ), Hansen and Falk-Petersen (2002) found that growth was highest when larvae were moved from 12 to 10 and later to $8{ }^{\circ} \mathrm{C}$, compared to constant temperatures. In Atlantic halibut (Hippoglossus hippoglossus, 160-400 g) reared at constant (11 and $14{ }^{\circ} \mathrm{C}$ ) or switched (14 moved to $11^{\circ} \mathrm{C}$ and vice versa) temperature regimes, Aune et al. (1997) found that growth rate was highest in fish transferred from 14 to $11^{\circ} \mathrm{C}$. This coincides with the $T_{\text {opt }} G$ for Atlantic halibut which has been shown to decrease from 14.9 to $12.7^{\circ} \mathrm{C}$ in the early juvenile stage (Jonassen et al. 1999). These findings are in line with results from the present experiment showing a decrease in temperature optimum with increasing fish size. Overall, the positive correlation between the thermal sum and growth indicates that high growth can be achieved in juvenile Atlantic cod by rearing juvenile cod in the temperature range of $13-16^{\circ} \mathrm{C}$ during the first months in culture.

In nature Atlantic cod larvae are poorly developed at hatching (approx. $4 \mathrm{~mm}$ ) with a relatively small yolk sac, which is completely absorbed after 5 days. They feed and live pelagically for several weeks and settle in coastal areas in benthic environments at 4-5 cm length (Pedersen and Falk-Petersen 1992). Observations on growth of wild juvenile Atlantic cod indicate that a size of 15-20 g can be reached 5-9 months after hatching (i.e. the same age as current experimental material) (Astthorsson et al. 1994; Björnsson et al. 2001). Compared with the higher optimum temperature for growth and the much higher growth seen in the present experiment this demonstrate that wild Atlantic cod seldom experience temperature conditions where their full growth potential can be achieved. Björnsson et al. (2001) pointed out the fact the benefits of selecting $T_{\text {opt }} G$ may be outweighed by other crucial factors such as feed availability, risk of starvation and predation risk. 

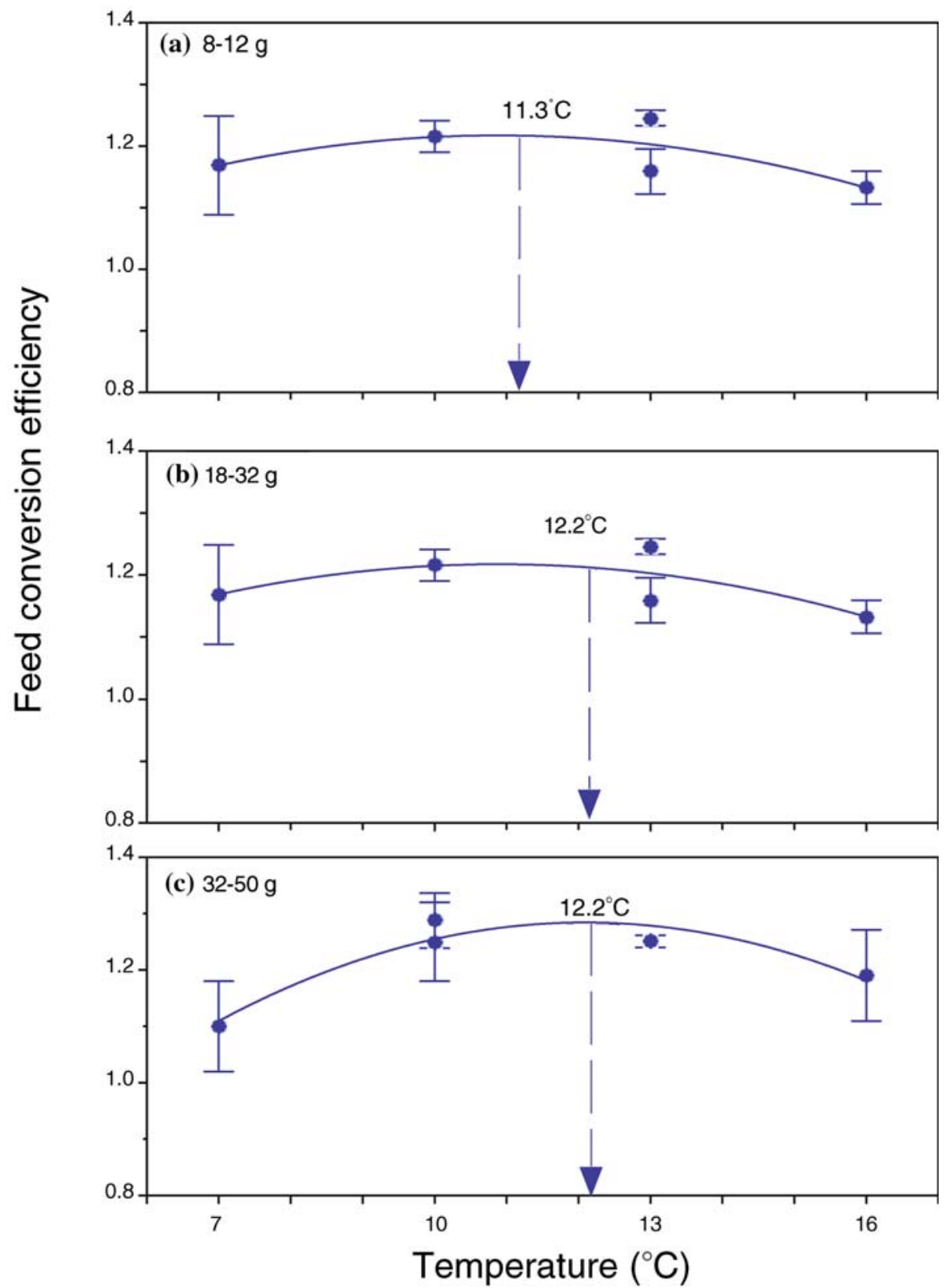

Figure 5. Changes in feed conversion efficiency (FCE) with temperature for three different size classes of juvenile Atlantic cod. The lines represent the least-squares second order polynomial fit to the data: $\mathrm{FCE}=a T^{2}+b T+c$ where $\mathrm{FCE}=$ Feed conversion efficiency, $T=$ temperature, and $a, b$ and $c$ are constants determined by the regression. Vertical lines indicate standard error of mean, $n=2$ for each data point. The T-step group is marked by square symbol. For the three size classes optimum temperature for growth $\left(T_{\mathrm{opt}} \mathrm{FCE}\right)$ indicated by the broken lines were calculated from the first order derivative of the parabolic regressions $(i . e$. when $d G / d T=0)$.

The significant effect of size on growth rate (Figures 3-4) is in accordance with studies on several fish species (Brett 1979, Fonds et al. 1992; Rijnsdorp 1993; Imsland et al. 1996; Jonassen et al. 1999) including cod (Pedersen and Jobling
1989). In the present experiment, size dependent growth was significantly influenced by temperature (Figures 3-4). There was an inverse relation between size and growth rate (Figure 3), except in the $7{ }^{\circ} \mathrm{C}$ group where no significant relationship 
Table 4. The relationship between feed conversion efficiency (FCE) and temperature in ${ }^{\circ} \mathrm{C}(T)$ estimated by a second order polynomial $\left(\mathrm{FCE}=a T^{2}+b T+c\right)$ for different weight range of juvenile Atlantic cod, $n=10$ for all three regressions

\begin{tabular}{llllllll}
\hline Weight range & $\mathrm{a}$ & $\mathrm{b}$ & $\mathrm{c}$ & $\mathrm{r}^{2}$ & $\mathrm{~T}_{\text {opt }} \mathrm{FCE}$ & $\pm \mathrm{SE}_{\text {range }}$ & $\mathrm{FCE}_{\text {max }}$ \\
\hline $8-12$ & 0.705 & 0.094 & 0.004 & 0.42 & 11.3 & $10.8-11.8$ & 1.24 \\
$18-32$ & 0.633 & 0.090 & 0.003 & 0.20 & 12.2 & $10.2-14.2$ & 1.18 \\
$32-50$ & 0.606 & 0.105 & 0.004 & 0.22 & 12.2 & $9.9-14.5$ & 1.25 \\
\hline
\end{tabular}

$\mathrm{FCE}_{\max }$ is the feed conversion efficiency at optimal temperature.

was found (Figure 3a). The stable growth rates seen with increasing size in the $7^{\circ} \mathrm{C}$ group are in accordance with our $T_{\text {opt }} \mathrm{G}$ calculations (Figure 4): at this sub-optimal temperature fish approach their optimum temperature range for growth as size increases, in line with the general pattern described by Brett (1979). The parabolic regressions (Figure 4) suggest an optimum temperature for growth of juvenile Atlantic cod in the size range 5-50 g to be between 14.7 and $12.6^{\circ} \mathrm{C}$, and decreasing with size. A similar decrease in $T_{\text {opt }} G$ with size has been reported for plaice (Pleuronectes platessa, Fonds et al. 1992), turbot (Scophthalmus maximus, Imsland et al. 1996), Atlantic halibut (Jonassen et al. 1999), Atlantic cod (Björnsson et al. 2001), and for fish in general (Cuenco et al. 1985). Atlantic cod appears to be rather eurythermal, which is expressed by high growth rates over a relatively wide temperature range. This also conforms to the benthic thermal range in the distribution area for Atlantic cod in the North Atlantic (Brander 1995). It is worth noting that the parabolic regressions between growth rate and temperature becomes less sharply defined with increasing size (Figure 4), indicating increasing temperature tolerance with size. This is in accordance with earlier studies on Atlantic cod (Björnsson et al. 2001), and other species (Brett et al. 1969; Elliott 1975; Imsland et al. 1996). Cuenco et al. (1985) indicated that, in general, the temperature optimum for growth in

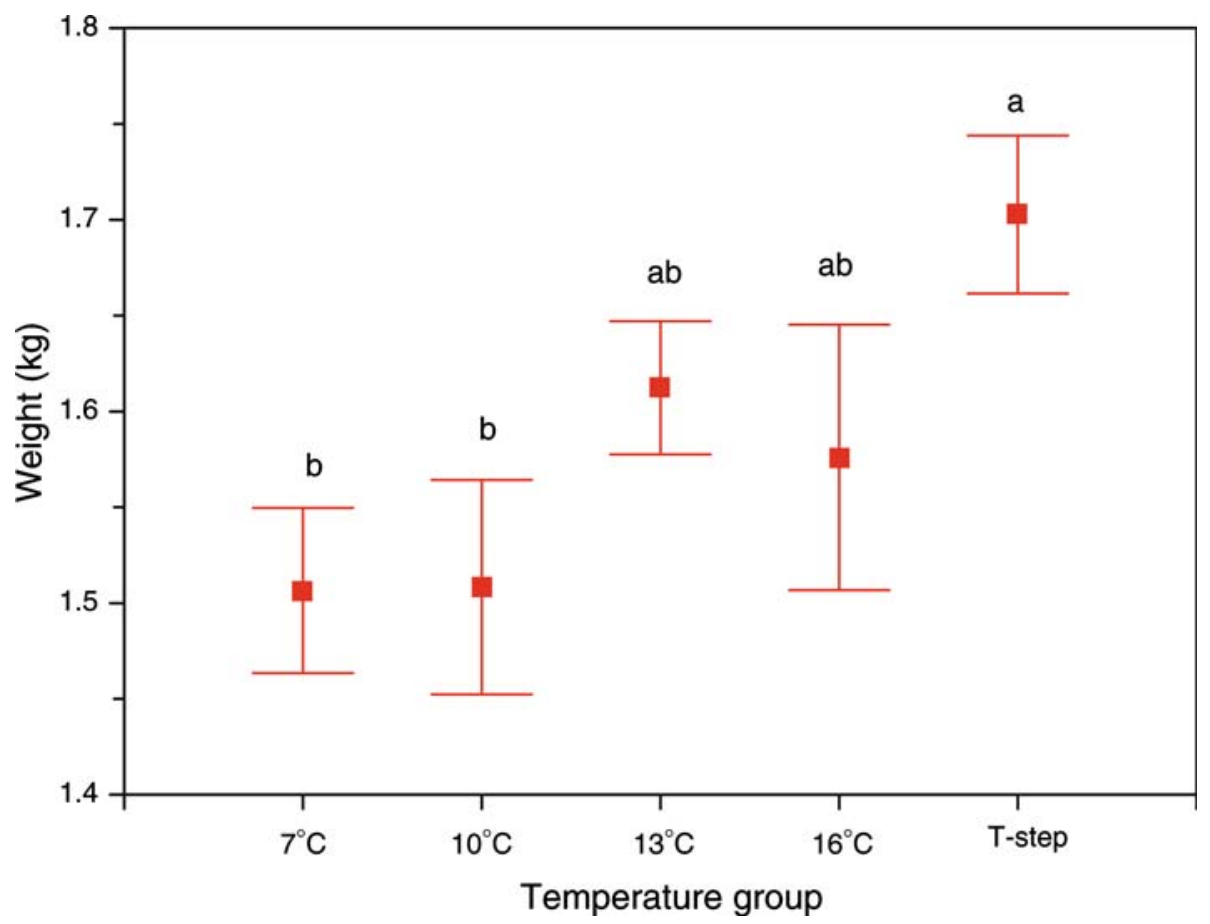

Figure 6. Mean weight of Atlantic cod reared five different temperature regimes during early juvenile stage and then reared in sea pens at ambient conditions for 17 months. Vertical line indicating SE may be obscured by symbol. Different letters indicate statistical differences (Fisher LSD test, $p<0.05$ ), with ' $a$ ' as the highest value, $n=20-43$ for each mean value. 
fish declines $1-2{ }^{\circ} \mathrm{C}$ with increasing weight in the range of $10-500 \mathrm{~g}$. Our findings are in line with these predictions as $T_{\text {opt }} G$ declines with $2.3{ }^{\circ} \mathrm{C}$ in the size range 5-50 g. Earlier studies with Atlantic cod have also indicated that the drop in $T_{\text {opt }} G$ is highest for the early juvenile stage (Björnsson et al. 2001; Björnsson and Steinarsson 2002) with a drop in $T_{\text {opt }} G$ from $17.3^{\circ} \mathrm{C}$ for $2 \mathrm{~g}$ cod to $10.7^{\circ} \mathrm{C}$ for $200 \mathrm{~g} \mathrm{cod}$, whereas $T_{\text {opt }} G$ is between 6 and $7{ }^{\circ} \mathrm{C}$ for 2-5 kg cod (Björnsson et al. 2001).

Calculated optimal temperature for feed conversion efficiency $\left(T_{\text {opt }} \mathrm{FCE}\right)$ is slightly lower than $T_{\text {opt }} G$ which is in line with findings on Atlantic halibut (Björnsson and Tryggvadóttir 1996), turbot (Imsland et al. 2001) and Atlantic cod (Björnsson et al. 2001). The suggested explanation for this finding is that at an unrestricted ration growth rate reaches a maximum at a temperature lower than that giving maximum ingestion rate (Jobling, 1994). Accordingly, as the temperature is lowered slightly below $T_{\text {opt }} G$ the growth rate decreases less than the ingestion rate, resulting in increased feed conversion efficiency (Björnsson and Tryggvadóttir 1996).

The high size rank correlation observed at all temperatures may indicate an early establishment of stable size ranks (hierarchies), which is common under culture conditions (Imsland et al. 1998). As in the present experiment, such hierarchies have been shown to form even under excess feeding (Ehrlich et al. 1976; Jobling 1982; McCarthy et al. 1992, Imsland et al. 1998). Alternatively, the changes in size distribution in the present study may have originated from inherent genetic differences in growth capacity of the fish (Imsland et al. 1998). This growth element, apparently, has some kind of "memory" (see discussion in Imsland et al. 1998) as we found an overall positive correlation between adjacent (i.e. $w_{e e k_{n}}$ and $w_{e e} k_{n+i}$ ) at all temperatures. As growth declined with increasing size (Figure 3), the correlation between initial and final growth rates can be interpreted as stable growth variation with increasing size.

In conclusion, the present study verifies a significant ontogenetic variation in optimum temperature for growth in juvenile Atlantic cod, with a reduced temperature optimum and an increased capacity for growth at lower temperatures as fish size increases. Moreover, our data show a possible mechanism for increasing feed conversion efficiency by "mimicking" thermoreg- ulative behaviour as juvenile cod reared at a temperature step regime had a lower feed intake, but higher feed efficiency compared to cod at constant temperature regimes. There may be a substantial gain in growth by rearing fish at high temperatures $\left(13-16{ }^{\circ} \mathrm{C}\right)$ during early juvenile stage as growth in a follow up trial in the sea indicated $5-13 \%$ gain in weight by applying a $\mathrm{T}$ step rearing regime in the land-based rearing phase. These findings may have important consequences for optimization of commercial production of Atlantic cod, but might also help to explain the motivation of cod migration.

\section{Acknowledgements}

This study was financed by the Norwegian Research Council (No. 156204/120).

\section{References}

Anonymous. 2005. Coastal Monitoring Along the Norwegian Coast. Institute of marine research, Bergen, Norwayhttp:// pegasus.nodc.no:8080/stasjoner/.

Astthorsson, O.S., Gislason, A. and Gudmundsdottir, A. 1994. Distribution, abundance, and length of pelagic juvenile cod in Icelandic waters in relation to environmental conditions. ICES Mar. Sci. Symp. 198: 529-541.

Aune, A., Imsland, A.K. and Pittman, K. 1997. Growth of juvenile halibut (Hippoglossus hippoglossus L.) under a constant and switched temperature regime. Aquac. Res 28: 931-939.

Björnsson, B. and Steinarsson, A. 2002. The food-unlimited growth rate of Atlantic cod (Gadus morhua). Can. J. Fish. Aquat. Sci. 59: 494-502.

Björnsson, B. and Tryggvadóttir, S.V. 1996. Effect of size on optimal temperature for growth and growth efficiency of immature Atlantic halibut (Hippoglossus hippoglossus L.). Aquaculture 142: 33-42.

Björnsson, B., Steinarsson, A. and Oddgeirsson, M. 2001. Optimal temperature for growth and feed conversion of immature cod (Gadus morhua L.). ICES J. Mar. Sci. 58: 29-38.

Brander, K.M. 1995. The effect of temperature on growth of Atlantic cod (Gadus morhua L.). ICES J. Mar. Sci. 52: 1-10.

Brett, J.R, Shelbourn, J.E. and Shoop, C.T. 1969. Growth rate and body composition of fingerling sockeye salmon, Oncorhynchus nerka, in relation to temperature and ration size. J. Fish. Res. Board Can. 26: 2363-2394.

Brett, J.R. 1979. Environmental factors and growth In: Fish Physiology Vol VIII. Bioenergetics and Growth. pp. 599675. Edited by W.S. Hoar, D.J. Randall and J.R. Brett. Academic Press, New York.

Bryan, J.D., Kelsch, S.W. and Neill, W.H. 1990. The maximum power principle in behavioral thermoregulation by fishes. Trans. Am. Fish. Soc. 119: 611-621. 
Chambers, R.C. and Miller, T.J. 1995. Evaluating fish growth by means of otolith increment analysis: special properties of individual-level longitudinal data In: Recent developments in fish otolith research. pp. 155-175. Edited by D.H. Secor, J.M. Dean and S.E. Campana. University of South Carolina Press, Colombia South Carolina.

Cuenco, M.L., Stickney, R.R. and Grant, W.E. 1985. Fish bioenergetics and growth in aquaculture ponds: II. Effects of interactions among size, temperature, dissolved oxygen, unionized ammonia and food on growth of individual fish. Ecol. Model. 27: 191-206.

Ehrlich, K.F., Blaxter, J.H.S. and Pemberton, R. 1976. Morphological and histological changes during the growth and starvation of herring and plaice larvae. Mar. Biol. 35: 105-118.

Elliott, J.M. 1975. The growth rate of brown trout (Salmo trutta L.) fed on maximum rations. J. Anim. Ecol. 44: 805-821.

Fonds, M. 1979. Laboratory observations on the influence of temperature and salinity on development of the eggs and growth of the larvae of Solea solea (Pisces). Mar. Ecol. Prog. Ser. 1: 91-99.

Fonds, M., Cronie, R., Vethaak, A.D. and van der Puyl, P. 1992. Metabolism, food consumption and growth of plaice (Pleuronectes platessa) and flounder (Platichthys flesus) in relation to fish size and temperature. Neth. J. Sea Res. 29: 127-143.

Fry, F.E.J. 1947. Effects of the environment on animal activity. University of Toronto Studies Biological Series 55: 1-62.

Gadomski, D.M. and Caddell, S.M. 1991. Effects of temperature on early-life-history stages of California halibut Paralichthys californicus. Fish. Bull. 89: 567-576.

Hansen, T.K. and Falk-Petersen, I.B. 2002. Growth and survival of first-feeding spotted wolffish (Anarhichas minor Olafsen) at various temperature regimes. Aquac. Res. 33: 1119-1127.

Hanson, J.M. 1996. Seasonal distribution of juvenile Atlantic cod in the southern Gulf of St. Lawrence. J. Fish Biol. 49: $1183-1152$.

Hill, D.K. and Magnuson, J.J. 1990. Potential effects of global climate warming on the growth and prey consumption of Great Lakes fish. Trans. Am. Fish. Soc. 119: 265-275.

Hintze, J.L. 1996. PASS Users Guide. NCSS, Kaysville, Utah.

Houde, E.D. and Schekter, R.C. 1981. Growth rates, rations and cohort consumption of marine fish larvae in relation to prey concentrations. Rapp. P.-v. Réun. Cons. Int. Explor. Mer. 178: 441-453.

Imsland, A.K., Nilsen, T. and Folkvord, A. 1998. Stochastic simulation of size-variation in turbot: possible causes analysed with an individual based model. J. Fish Biol. 53: 237258.

Imsland, A.K., Sunde, L.M., Folkvord, A. and Stefansson, S.O. 1996. The interaction between temperature and size on growth of juvenile turbot. J. Fish Biol. 49: 926-940.

Imsland, A.K., Foss, A., Gunnarsson, S., Berntssen, M., FitzGerald, R., Bonga, S.W., Ham, E.van, Nævdal, G. and Stefansson, S.O. 2001. The interaction of temperature and salinity on growth and food conversion in juvenile turbot (Scophthalmus maximus). Aquaculture 198: 353-367.

Jobling, M. 1982. Some observations on the effects of feeding frequency on the food intake and growth of plaice, Pleuronectes platessa L. J. Fish Biol. 20: 431-444.

Jobling, M. 1994. Fish Bioenergetics. Chapman and Hall, London.
Jobling, M. 1997. Temperature and growth: modulation of growth rate via temperature change In: Global Warming: Implications for Freshwater and Marine Fish. pp. 225-253. Edited by D.M. Wood and D.G. McDonald. Cambridge University Press, Cambridge, UK.

Jonassen, T.M., Imsland, A.K. and Stefansson, S.O. 1999. The interaction of temperature and size on growth of juvenile Atlantic halibut. J. Fish Biol. 54: 556-572.

Kristiansen, T.S., Michalsen, K., Jacobsen, J.A. and Huse, I. 2001. Optimal selection of temperature areas by juvenile cod (Gadus morhua L.) in the Barents Sea modelled by dynamic optimisation. ICES J. Mar. Sci. 58: 172-182.

Kuzmina, V., Glatman, L., Drabkin, V. and Gelman, V. 2003. Amylolytic activity in fish intestinal mucosa: temperature effects. Comp. Biochem. Physol. B - Biochem. Mol. Biol. 134: 529-534.

Lafrance, P., Castonguay, M., Chabot, D. and Audet, C. 2005. Ontogenetic changes in temperature preference of Atlantic cod. J. Fish Biol. 66: 553-567.

Larsson, S. 2005. Thermal preference of Arctic charr, Salvelinus alpinus, and brown trout, Salmo trutta - implications for their niche segregation. Env. Biol. Fish. 73: 89-96.

Luczkovich, J.J. and Stellwag, E.J. 1993. Isolation of cellulotic microbes from the intestinal-tract of the pinfish, Lagodon rhomboides, size-related changes in diet and microbial abundance. Mar. Biol. 116: 381-388.

McCarthy, I.D., Carter, C.G. and Houlihan, D.F. 1992. The effect of feeding hierarchy on individual variability in daily feeding of rainbow trour, Oncorhynchyus mykiss (Walbaum). J. Fish Biol. 41: 257-263.

McCauley, R.W. and Huggins, N.W. 1979. Ontogenetic and non-thermal seasonal effects on thermal preferenda of fish. Am. Zool. 19: 267-271.

Michalsen, K., Ottersen, G. and Nakken, O. 1998. Growth of North-east Arctic cod (Gadus morhua L.) in relation to ambient temperature. ICES J. Mar. Sci. 55: 863-877.

Pálsson, Ó.K. and Thorsteinsson, V. 2003. Migration patterns, ambient temperature, and growth of Icelandic cod (Gadus morhua): evidence from storage tag data. Can. J. Fish. Aquat. Sci. 60: 1409-1423.

Pedersen, G. and Falk-Petersen, I.B. 1992. Morphological changes during metamorphosis in cod (Gadus morhua L.), with particular reference to the development of the stomach and pyloric caece. J. Fish Biol. 41: 449-461.

Pedersen, T. and Jobling, M. 1989. Growth rates of large, sexually mature cod, Gadus morhua, in relation to condition and temperature during an annual cycle. Aquaculture 81: 161-168.

Reynolds, W.W. and Casterlin, M.E. 1979. Behavioral thermoregulation and the 'final preferendum' paradigm. Am. Zool. 19: 211-224.

Rijnsdorp, A.D. 1993. Relationship between juvenile growth and the onset of sexual maturity of female North Sea plaice, Pleuronectes platessa. Can. J. Fish. Aquat. Sci. 50: 16171631.

Robinchaud, D. and Rose, G.A. 2004. Migratory behaviour and range of Atlantic cod: inference from a century of tagging. Fish and Fisheries 5: 185-214.

Scheffé, H. 1959. The analysis of variance. John Wiley \& Sons, New York, NY.

Schmidt-Nielsen, K. 1990. Animal physiology: adaptation and environment (4th ed.). Cambridge University Press, Cambridge. 
Sokal, R.R. and Rohlf, R.J. 1995. Biometry (3rd ed.). WA Freeman, San Francisco, CA.

Wildhaber, M.L. and Crowder, L.B. 1990. Testing a bioenergetics-based habitat choice model: Bluegill (Lepomis macrochirus) responses to food availability and temperature. Can. J. Fish. Aquat. Sci. 47: 1664-1671.
Zar, J.H. 1984. Biostatistical analysis (2nd ed.). Prentice-Hall, Englewood Cliffs, NJ.

Zinichev, V.V. and Zotin, A.I. 1987. Selected temperature and optimums for development in prolarvae and larvae of chum salmon, Oncorhynchus keta. J. Ichthyol. 27: 141-144. 